\title{
How Do Start-Up Companies Explore the Strategies to Pursue Market Share and Benefits-Take Maotai-Flavor Liquor in Renhuai as an Example
}

\author{
Jia'e Wang \\ Hainan University, Haikou, China \\ Email: 2296635505@qq.com
}

Received 24 January 2015; accepted 19 February 2015; published 25 February 2015

Copyright (C) 2015 by author and Scientific Research Publishing Inc. This work is licensed under the Creative Commons Attribution International License (CC BY). http://creativecommons.org/licenses/by/4.0/

\section{(c) (i) Open Access}

\begin{abstract}
Maotai originates from the famous capital of porcelain in China-Renhuai city. With the conduct of the State Council Document (No. 2) in 2012, Maotai-flavor liquor steps into the market, with its geographical advantages richly endowed by nature and historical goodness. Industry of Maotaiflavor liquor rapidly emerges in Renhuai. As a representative, the development situation of Maotai has a bright future, with the collection of raw materials, production, supply, sales in one of the state-owned enterprises. It works as the second aircraft carrier after Maotai group, mainly named as "Chinese wine capital-Renhuai", setting up by Renhuai government and relying on the attraction of original geography. By the means of developing provincial agent and investment for marketing, it aims to increase the area's GDP and Maotai-flavor liquor's market share. Adhering to the principle of honesty and trustworthiness, gaining profit as well as making production and management philosophy, "the most fragrance Maotai-flavor liquor in the world originates from Renhuai" makes healthy Maotai-flavor liquor culture in China. Wine is a special drink which has been given to man by god. In a sense, the history of the Chinese nation is the history of wine culture and Chinese culture with wine culture has combined closely to each other. Wine has been Chinese people's bone marrow. Wine industry is a traditional industry, a never declined human society, shining farming civilization brilliantly, full of the wisdom of creation and cultural charm.
\end{abstract}

\section{Keywords}

Maotai-Flavor Liquor, Local Pillar Industries, Market Trends, The Concept of Health 


\section{Renhuai Maotai-Flavor Liquor Co. Ltd.}

\subsection{Introduction}

Wine-more natural, more better. With the theme in "the next ten years, the Chinese liquor depends on Guizhou and Guizhou wine relies on Renhuai” and the inspired main melody of Maotai-flavor liquor steps into the market, Renhuai Maotai-flavor liquor Co. Ltd. established rapidly, which owned the collection of raw materials, production, supply and sales in a state-owned enterprise. Following Maotai Group’s suit, it works as the second aircraft carrier after Maotai Group. The company’s production bases and warehouses base are adjacent to Maotai Group. In this way, it can share the unique natural environment advantages, production technology, Koji making technology and blending techniques with Maotai Group.

The company has 95 buildings of production workshops. Its annual outputs are around 33,000 tons. Annual stock balance is about 54,860 tons. It holds 36 packing lines, has 55 aptitude bartenders, 77 qualified wine tasters and over 6000 industrial workers.

\subsection{History}

During Shang dynasties, the Xianyun Hole, which is located in the eastern of Renhuai city, is unearthed the earliest wine dispenser, drinking vessel among Guizhou history, which proved Renhuai has a long history of making and drinking wine.

In 135 BC, the famous emperor Hanwu came to Yelang (previous refer to Guizhou province), after tasting Jujiang wine (previous Maotai) and praised "luscious". From then on, there is a poem called "People did not know what is Jujiang Wine (Previous Maotai)”, whose specially mellow characteristic attracts Tang Meng from the Western Han Dynasty.

From 1704 to the late Ming and early Qing Dynasty, Maotai become unique wine all over the world, Maotai flavor liquor come into being day by day. At first, with the symbol of "Huisha Maotai" "Maotai spring" "Maotai incense” as its famous brew.

In 1915, Maotai wine honored with a Gold medal in Panama International Expo. Henceforth, Maotai flavor liquor becomes famous and unique around the world.

In 1935, the Chinese red army of workers and farmers come to Maotai town, they use Maotai wine to heal themselves, and primer Chou also said, Maotai wine made great function on the victory of the revolution.

In 1949, primer Chou use Maotai as the main wine in the Founding ceremony.

In 2004, Renhuai honored with “The capital of porcelain in China”, which turn a new life in the development of Renhuai Maotai flavor liquor.

In 2013, Renhuai Maotai-flavor liquor Co. Ltd. Set up by Renhuai government for the sake of development of Renhuai Maotai-flavor liquor standardiesd and unified [1]-[8].

\subsection{Current Situation}

Wine industry is one of the pillar industries in Renhua, after the city was known as "The capital of porcelain in China” in 2004. It was honored as "the model city of new industrial (the national excellent wine) in China” by The State Ministry in 2010, based on Maotai. Renhuai Maotai-flavor liquor is working as the main economic resources. By 2012, Renhuai has 392 local wine business enterprises, among which 208 register at the administrative department of industry and commerce to get their business license, and 143 get their national production license. Still 136 enterprises don't get the production license but run as the legitimate business. Among 300 wine marketing enterprises, 36 are in the line of the municipal scale and 12 have been selected as "the biggest, the ten stars, the fifth strongest enterprises” in Zunyi.

There are over 1350 registered trademarks about wine. 2 of them are the well-known trademark; 53 belong to provincial well-known trademark; 6 of them are provincial well-known brand and 12 have passed through the ISO9000 quality certification. In 2010, the scale of Renhuai Maotai-flavor liquor achieves the total industrial value of out-put to 176 billion RMB, taking up to 96 percent of the total value of out-put of Renhuai city. The total wine production output achieves 13.6 million litres (equal 12.1 million tons).

\subsection{Developing Target}

The Renhuai Maotai-flavor liquor has being booming. The whole local wine enterprises are heading for Renhuai 
wine industrial park. The overall situation is "development fast-up, transformation speed-up, performance enhancement, people's livelihood improvement, after effect increased".

Absolutely, wine industry is the main economic development force. It is the support of Renhuai city's “Double Billion” developing strategy, which contributes Maotai Group’s process to becoming bigger and stronger. At the end of the 12th Five Year Plan, Renhuai government plan and make sure that the local wine production output could be reach to double of the original scale, to over 50 million litres, strive for 60 million litres, the total value that wine bring is to 1000 billion. Bring in 100 go beyond the qualification of wine enterprises, province brand and landmark production attempted to exceed 100 enterprises. The final target is to make Renhuai become the biggest Maotai-flavor liquor' production base around China.

\section{Marketing Strategy Analysis}

\subsection{The Overall Conception}

The overall conception of implement under the advocation of [No. 2.2012. state council Document] makes the grand goal of "the next ten years' liquor industry depends on Guizhou and Guizhou wine relies on Renhuai" come true.

Renhuai city is the home of Maotai-flavor liquor in our country. Renhuai wine's total production, output value, profit and tax all take up over 80 percent of Guizhou province. In 2012, the total production was 30 million litres. It is hopeful to be 50 million litres at the end of the 12th five year plan, even to be 60 million litres. The purpose of overall production value is 1000 billion litres. Other goals are building "the most excellent and biggest production base of Maotai-flavor liquor" and supporting the development for Guizhou wine industry, rapidly.

Above all, the goals are winning the market share (up to 10 percent or so) of Maotai-flavor liquor, making sure that the wine production value is 1300 billion RMB, striving for 1500 billion production value, getting much room to realize higher target and significant progress and winning over Guizhou wine's market share (20 percent) around the whole wine industry of China in 2020.

\subsection{Method of Marketing}

Based on market demand, concentrating on brand construction, in order to build a well-developing environment, for local wine enterprises, to structure " $1+20$ " style (Maotai Group plus 20 local wine groups whose annual marketing reach over a billion), to set up aircraft carriers, well-building model bases and relating industrial parks of wine, the eco-development idea- “Green, Organic, Technology" is stressed. In order to enhance the level and speed-up the main enterprises, brand products and its scale process, Renhuai maotai-flavor liquor company takes a new road to industrialization, combines informationization with industrialization, integrates resources, maintains the stronger and give up the weaker, depends on new technology and creative idea to improve competitiveness of Renhuai wine and improves Renhuai Maotai-flavor liquor's influence among the whole wine market to be worthy of the name of "The capital of porcelain in China" even "The capital of porcelain around the world".

\subsubsection{The Three-Pronged Approach}

To enlarge the scales and qualification of enterprises,

The first step is to support for the large development of Maotai Group, strongly.

The second is to put much strength to build Renhuai special liquor industry parks, to support the parks in focus, making sure spend little but bring the largest profits.

The third is to work as a team with partners who have strong capital, rich management experiences and resourceful investors and are familiar with market-net.

When it comes to the market share of Maotai-flavor liquor, the total production all over the country is over 1300 billion litres. But Guizhou Maotai-flavor just held 2.46 percent in 2013. However, our Maotai-flavor liquor's profits tax rate is up to 30 percent. Why?

The reason is that Renhuai jiang-flavor wine is high-quality, uses traditional secret making methods, tends to be more wholesome and focuses on the health idea that has been drawn much attention nowadays. Renhuai Jiang-flavor which depends on the unique climate feature in Guizhou and the traditional healthy brewing methods has been regarded as green and healthy wine obviously, increasing popularity around the wine market. 
"But the idea could not make the most people believe just depending on the small-scale enterprises to blow their own horn. For this reason, our government must show up to improve the credibility and qualification, only in this way can our Remhuai Jiang-flavor liquor be known more, farther and wider.” said the mayor Maocai Wang.

The local government has organized over 40 wine enterprises in Shanghai, Shenzhen, Beijing and so on. They hold large-scale commerce meetings and invite local politicians, famous enterprisers, the media from home and abroad to promote the development, traditional industry and healthy faith of Renhuai Maotai-flavor liquor.

\subsubsection{Taking Renhuai as the Base, Radiating the Whole Country}

According to Renhuai's developing situation, local governments act as the header, making reasonable and proper unified plan, integrating every local wine Group and enlarging Maotai-flavor liquor's marketing competitiveness. It is based in Renhuai, and ultimately, improves the whole country's wine industry's developing all-around. Renhuai government has being taking capital attracting measures, working hard to strengthen Renhuai Maotaiflavor liquor enterprises’ market power, promoting local economy, and increasing its GDP rate, actually, to support the theme of "The capital of porcelain in China” developed comprehensively.

\section{Market Positioning}

Philip Kotler said, market position refers to a company design products and images for itself in order to make sure the irreplaceable and valuable position among their target customers.

According to Kotler's theory, market position should be taken from character of products, profits supported by products, occasion using and competing rivals. Marketing position attempted to take advantage over the rivals. To gain the upper-hand position, we should understand the rivals' advantages, which come from the differential both products and service, people as well as images, in accordance with the market analysis, Renhuai Maotai-flavor liquor's market position should be divided into three aspects.

\subsection{Different Blessing Occasion Market}

According to different needs in different blessing occasions, there are four kinds of Renhuai Maotai-flavor liquor special for various meanings, we called: $\mathrm{Fu}, \mathrm{Lu}$, Shou, $\mathrm{Xi}$ in Chinese. China has long history about blessing worlds. They always pay much attention on worlds and behaviors culture, especially those worlds meaning well.

Four kinds of wine of Renhuai Maotai-flavor liquor's market price is from about 108 RMB to 198 RMB. Such reasonable price decision can get more market competition advantages and target consumers.

\subsection{Private Consumption Market}

Wine has divided into three different classes: the high-class, the middle-class and the low-class. Renhuai Maotai-flavor is from the point of people. Its price position is more reasonable and affordable for most people although it is sticking to three classes dividing. The market price of the high-end is just around 498 RMB, and the low-end is around 298 RMB. Making such price decision is taking full consideration of Renhuai Maotai-flavor liquor's reality, which will be helpful for such new enterprise to their market competing with other kinds of flavor liquors.

As a new state-owned enterprise, Renhuai Maotai-flavor liquor Co. Ltd. mainly focuses on the middle and law-class markets, for lacking of enough capital and strong market share. There still exist great opportunities and challenges for the development of Renhuai Maotai-flavor liquor.

\subsection{Different Target Ages Stage}

With historical process development opportunity reality, the 80s and the 90s have becoming the main force in the next years. Renhuai Maotai-flavor liquor is aiming at the young generations, working based on market needing and developing its wine industry, uniquely.

With regard to more and more people are caring about food safety and as the traditional wine industry sticks to making healthy wine, Renhuai government insists the concept of health, strengthening local wine's supervision to make sure more and more people from stages and ages know Renhuai Maotai-flavor liquor and drink Renhuai Maotai-flavor liquor and makes the objective which is to expand Renhuai Maotai-flavor liquor's mar- 
ket prospect come true, ultimately.

\section{The New Plan}

Renhuai city is built based on wine, developed up by wine and also strengthened relying on wine. Wine industry is its pillar industry and unique advantage.

Guizhou province as well as the local government catches up the new opportunities and puts forward new develop ideas which will make great effect on Renhuai Maotai-flavor liquor' booming and will support and strengthen Renhuai jiang-flavor liquor.

\subsection{Strategy of "Saving Land" and "Intensive Style"}

Renhuai Maotai-flavor liquor has been booming and local wine enterprises coming into the unified industry rapidly. There is no doubt that Renhuai is a place where can make the most excellent wine for the long history and the unique geographical advantage. However, the land in Renhuai city is as expensive as gold, so how to solve the problem has become the first thing.

The methods of "land saving" and "enlargementing style" have been approved. Maotai County plans to spend 52 billion RMB to integrate and rebuild the city considering local people with environmental harmonious. The core of Renhuai wine is its distinctive Jiang-flavor and geographical and historical effect. Absolutely, Maotai Group is the biggest strength on the local economy. It becomes the strongest engine and center-heart for the development of Local wine's developing scales in Renhuai city. Production as well as its all-round promotion has become the main force for Renhuai.

"The next ten years, China liquor depends on Guizhou; Guizhou wine relies on Renhuai" and "Maotai-flavor liquor production bases' effects" have become obvious.

Take the most use of local terrain advantages and avoid its disadvantages, the problem for lack of land has been solved wisely. The poor land in the past has turned into cornucopia. The harmonious win-win results have been realized between farmers and enterprises, which is honored as the most successful model among Yun-Gui plateau.

In August 2011, Guizhou Renhuai development zone has been approved by provincial-government, on the basis of development of Renhuai city. It integrates the original-industry park model, planning to build "one zone three park, one park and more points" development model, to achieve the goal of developing Maotai-flavor liquor into the leading industry, innovative and sustainable, to be a way to bring others same industry's development.

Guotai wine Group saves 50 percent land by changing its traditional manufacturing shop working style. The total investment is high up to 14,000 million per hectare. In the zone, the enterprises are over to 4500 million per hectare. At present, the project has created building land over $7000 \mathrm{Mu}$, among which exceed $5000 \mathrm{Mu}$ is developed from sloping.

\subsection{Further Developing Strategy, Protection for "Meijiu River"}

From the year of 2014, Maotai Group will spend 5000 million RMB every year on protection of Chishui River and the around Eco-Environment during 10 years. (The fees will be 5 billion in total.)

From the press conference on "the Revolution and Limitation along Chishui River's civilization construction, ecologically, on July $4^{\text {th }}$, 2014", we learn that our province has put 26 billion RMB into the Chishui River's wastewater control from the $12^{\text {th }}$ five year plan, most of which are being used in wine enterprise's standard construction and polluting projection.

\subsection{Creating the Legend of "China's Wine Capital"}

Famous Maotai wine is the typical representative for Renhuai as well as the whole Maotai-flavor liquor around the country.

On one hand, Renhuai owns over 3000 registered Maotai-flavor liquor brand including a series of Maotai. Among most of these enterprises, there surely are lots of high quality wines, but their market influences are too small to be recognized openly. Until now, many consumers just think Renhuai only owns Maotai.

On the other hand, the legend of Maotai has come under greater scrutiny in recent years amid public anger at 
excessive government spending on such events, also on such problems of faking wine, etc. All of such events have put great pressure on wine marketing, which undoubtedly brings much unfavorable factors for Renhuai local economy.

So, in what way can we do with such dilemma occasions, and how can Renhuai face with the difficulties successfully?

\subsubsection{Lacking of Brand Influences}

"Lets us think it over that in a similar making-environment and equally standard methods, now that people know Maotai wine is better, can the wine of other brands produced in Renhuai be bad?”

"Guotai, China's top grade, Laishijia wine..." When driving to Renhuai, we can see many wine advertisements catching our eyes from time to time. The more to Renhuai, the more advertises. People even can see over 10 wine brands advertisement at the same time at one place.

Since Renhuai has been honored as "The capital of porcelain in China", many people still are not acquainted with such thing. Lots of limitations still exist. Most people know Maotai wine, but only a small number of them know that Maotai is produced in Renhuai. What'S more, even they know that Maotai wine is produced in Renhuai, they do not know many famous wines are produced from Renhuai, such as Guotai wine and Diaoyutai which we heard many times.

There is an embarrassing situation. Renhuai produces many high-end liquor. However, except for the famous and traditional brands-Maotai and Huai wine, many other brand influences are still very weak and lack of popularity.

\subsubsection{Building up Renhuai Maotai-Flavor Liquor's Brand}

Faced with over 3000 Maotai-flavor liquor brand, how to let consumers appreciate that Renhuai jiang-flavor is much better?

The government believe that, in order to improve market popularity and set up Renhuai Maotai-flavor's zone brand, it needs to take some measures to strength brand conscious, through "Made procedures standardized, unification normalized and personality be tasted.”

Renhuai has two main wine brands, one is Maotai, the other is Renhuai Maotai-flavor, through which it will boost the brand construction of Renhuai local liquor. Furthermore, it can avoid some others illegal enterprises taking advantages of Maotai to do some harmful thing seven some illegal marketing behavior.

In 2013, the brand "Renhuai Maotai-flavor liquor" has been issued by the State Administration for Industry and Commerce for Geographical Indications "Trademark" certification. After then, "Renhuai Maotai-flavor liquor” can be seen in National Geographic Trademark Culture Museum.

We can see the two symbol logos on Renhuai Maotai-flavor liquors' package. increasing products has been printed with them. However, building Renhuai jiang-flavor brand is a comprehensive and systematic mission. It still has a long way to go.

\subsubsection{Industrial Layout Planning Should Be Reasonable}

Previously, Guizhou province came out of the theme of "the next ten years China liquor depends on Guizhou; Guizhou wine relies on Renhuai”. So, after all, Guizhou wine relies on Renhuai, on what? On quality and profits instead of quantity.

There is no point that depends on quantity. For example, the wine production of Sichuan is 350 million kilolitres a year. However, Renhuai just has 30 million kilolitres a year. Renhuai is not able to compete with Sichuan. Based on the local reality, Renhuai government must learn how to improve its competition on both quality and profits.

Firstly, illegal development zone should be banned strictly. It is unavoidable to cause some pollution during the production process. To keep Maotai Group's importance status, some other wine industries on the upstream of Meijiu River should not be allowed taking the already existed enterprises out.

Secondly, the development zone should be limited. There exist some enterprises which make little profit in Renhuai. These enterprises should be encouraged to turn their business to be engaged in storage and logistics and try to replace business.

Thirdly, make the development zones standardized. Measure the down stream of Maotai with specifications and then provide some political supports. 
In the meantime, Renhuai government also takes a widely scope city rebuilding.

\subsubsection{Enlarging Capital Attraction}

Centering on building Renhuai Maotai-flavor liquor's brand, Renhuai government has established Renhuai Maotai-flavor liquor Co. Ltd.

Working as a state-owned enterprise, collecting raw materials, production, supporting and sales from one line, it has production workshops 95 and 3916 production pits. The annual production competence is up to 33,000 tons. Meanwhile, Renhuai puts much focus on capital attraction in recently years, expecting more external forces to join so as to realize win-win goal. Although the fruits of this method have seen a bright effect, it does not mean that Renhuai government opens the door to ever investors unconditionally. They still have more selectivity and are strictly and widely.

\section{Environment Analysis}

Environment Analysis refers to all forces that influence the whole industries and enterprises. Analyzing from the macro environment, every industry and enterprise will lead to different results according to their own characteristics and needing reality, generally speaking, often analysis from political, economical, social, and technological aspects to conduct.

\subsection{Political and Legal Factors}

At present, our country's socialist market economic system has constructed. Law and economical system is improving. Our country has clearly defined on the certification of market subject's confirmation, property protection, marketing behaviors and so on. Now, we are at the state of high development period. Political environment is stable. It is the golden time for Renhuai Maotai-flavor liquor's development. After China joins into WTO, which brings new chances to our Maotai-flavor liquor, we should make it clear that foreign wine will bring much pressure to our native wine.

In January, 1996, the State Administration of Industry and Commerce carried out the document of "Advertising management measures of wine", in which the Article 7 and Article 9 make it clear on wine advertisement's contents and quantities. It makes the cost of wine increased. In order to protect entrepreneurs' benefits, the state also carried out many other related documents, such as "Distribution management and retail standard of wine" and "Distribution management and wholesale specification of wine". All of them are helpful to Renhuai Maotai-flavor's development.

\subsection{Economic and Population Factors}

According to National Bureau of Statistics, now the total population in our country is about 13 billion and the statistics will boom in the future. The total population in Renhuai is about 5 million. The population characteristics in our country are the large population and the quantity predicted will be up to 16 billion in the middle of $21^{\text {st }}$ century. At that time, the population will show a stable increasing rate. Such situation will be undoubtedly a great period of time for the development of wine industry as well as Renhuai Maotai-flavor liquor.

In recent 20 years, our country's economy is booming, especially from 2004 to 2007. The GDP increasing rate exceeded 10 percent. The GNP and purchasing power has improved a lot. In 2012, Renhuai's total value of out-put was 330 billion RMB. The revenue was 114 billion RMB, and finished real-investment was 124.9 billion RMB. Per capita disposable income in city was 20656 RMB. Farmer's was 6752 RMB. Economic force is the leading position in Guizhou province as well as the southwest of China.

Although having been influenced by economic crisis, China is keeping developing, overall in a good condition. Renhuai Maotai-flavor liquor's aim is that the increasing rate speed is up to 32 percent in recent years in domestic market. Maotai-flavor's market share has increased about 20 percent, according to the report from Chinese Liquor Industry Association. So we look forward to challenges and bright future of Renhuai Maotai-flavor liquor.

\subsection{Social and Cultural Factors}

Chinese wine has a long history. It is over one thousand years. Early in Shang dynasty, Chinese has known how 
to make wine from distiller. Among China’s long history of food culture, wine culture is an important part of it, mainly including: nutrition and health culture, the art of color, aroma and taste, the diet custom, striving for personal diet culture and the whole idea, behavior, emotion, language, science as well as creative art and so on, which are related with the process of consuming. With a long history of wine, almost every occasion could not go on without wine.

With so many food issues in recently years, people are more and more caring about the issues of food safety, taking serious attitude towards food and health. The people in the 80 s and the 90 s act as the main consuming force in the future. They are growing up in a highly development times. Marketing economy and social reformation have a great effect on their senses of value even on their self-behaviors. The globalization, the information and the network have already become the major tendency when the society develops. How traditional wine industry brings up the new generation to become the main consuming force is a great challenge for Renhuai Maotai-flavor liquor's market development.

\subsection{Resources and Environment Factors}

Renhuai is rich in resources, with unique geographical shape, climate, soil water, microorganism, raw materials and brewing process, all of which are doomed to be the representative for Maotai-flavor liquor. And such unique environment has been sustaining Maotai-flavor's production and development.

At present, the urbanization in our country has being faster and faster. A large scale of farmer-land has been taken up for city building and infrastructure construction, which leads to reduction of output and higher price. As a result, the cost of making Maotai-flavor liquor becomes high.

With the rapid progress of technology, to improve the production output of wine, a new method of combining liquid liquor with brewing technology has been created. Application of new technology in production process, wine making technology and modern detection methods has made significant progress.

The introducing of many kinds of new advanced equipment in recent years and the serious attitude for healthy food enable people to have a more profound understanding of Maotai flavor liquor, which lays the foundation for Renhuai Maotai wine developing toward a more scientific direction and is helpful to Renhuai Maotai wine company to produce more health products suitable for people's different tastes.

\section{Cooperation Citizenship}

\subsection{Admiration: Original Ecology Is Power}

As the most important Guizhou wine's production base, Renhuai city not only takes the responsibility of supporting and protecting Maotai wine, but also develops the origin base of state liquor's basis. Meantime, other local wine industries should take the same missions.

Renhuai not just works as "the ten most developed counties in Guizhou province" and "the hundred strongest cities and counties in the southwest of China”, but the original place of Maotai wine and the home place for Eco-Maotai-flavor liquor. "Original ecology is not only power, but also the whole Maotai-flavor liquor's history base”.

With regard to original ecology, "stabilization and sustainability” of the environmental Renhuai Maotai-flavor liquor are the key points. Maintaining original ecology is the way for Renhuai’s development.

\subsection{Protection: Traditional Culture Is Heritage}

Every culture absolutely needs strong protection. National wine is the pillar. Maotai is the tap. Only by following the pillar and tap's suit can Renhuai Maotai-flavor liquor have the room to develop. Thus by the means of lawful, politics and economy are the stable strategies for many years upon Renhuai wine industry. The local government has carried out related policies many times to standard Renhuai wine industry.

"Traditional culture is heritage." said Loubing (mayor of Renhuai city). "We cannot talk about development without culture”. In recent years, the local government has taken strong actions to protect Renhuai Maotai-flavor liquor.

\subsection{Inheritance: Carry Maotai-Flavor through to the End}

As we all know, Renhuai Maotai-flavor liquor has a long history and is creative all the time. 
It is not a legend to drink and then becomes healthy. With regard to such idea in heart, it has brought in more room for Renhuai wine's market caving out widely. Its leading role in market makes local people rich.

\subsection{Development: Form Style of Industrial Cluster}

Industrial cluster is the necessary mode that Renhuai must stick to.

Persevere in scale, standard and brand, take the measure of $1+20$ brand strategy, which means to maintain the unique world-class brand of Maotai, and create 20 areas brands that owned self-intellectual property and annual production value must exceed up to 5000 million.

The second strategy is based on existing resources to encourage and leads local wine enterprises to unify, merger and rebuild. Bringing up local brand and then forming brand team, it insists on the way of Industrial Cluster. Before 2010, it focuses on building five to ten wine enterprises with capital over one billion.

\subsection{Confusion: Expect "Relax" on Policy}

“Why Sichuan wine can develop strongly and successfully but Guizhou wine cannot ?" There is no doubt that Renhuai will meet opportunities, challenges, advantages and confusions if Renhuai wants to develop strongly. Although Renhuai has abundant resources, wine industry can develop rapidly with industrial cluster. However, it lacks land, space, and clumsy on function. It is difficult to work well.

With support of the government, Renhuai wine industry makes great contributions to the better development of Guizhou province.

\subsection{Responsibility: Maotai Wine Is Pillar}

The responsibility of Renhuai is not only the responsibility for Renhuai people but also for successive governments. The responsibility of Renhuai is to keep the brand "The capital of porcelain in China" building-well, to lay a strong foundation for this brand on its industrial base and cultural heritage, develop ecological agriculture in order to support national wine with high-quality and healthy raw materials and to protect ecological environment for the sake of maintaining Maotai wine's living eco-environment.

\section{Analysis for Development Prospects}

Renhuai is a wine city. This truth allows no dispute. This is one of Renhuai's characteristics.

In 2011, Renhuai wine industry finished total wine production of 19.8 million kilo-hiters, which took up to high proportion of 80.3 percent among the whole provincial wine quantity and achieved total industrial value of 235.4 billion RMB. In 2012, Renhuai realized total value of 330 billion RMB. Total government operating revenue was 114 billion RMB. Total social retail sales of consumer goods were 46.5 billion. In 2013, total wine production quantity was 30 million kilo-litres. Total tax was 147 billion RMB among which wine industry's value added 297 billion RMB. The proportion of GDP was around 70 percent.

Those statistics prove that Renhuai wine is most valuable. Enterprises surly fall in love with it. Why? The reasons are unique resources, valuable quality and sticking to the idea of health. All of them are the core for its competition. This is another character.

In recent three years, local production value, total government revenue, and local average government revenue were 28 percent, 67 percent, 51 percent respectively. Total wine production was 30 million kilo-litres per annual. Aiming at 2015, it strives for wine production to 60 million kilo-litres. Total industry value is to 1000 billion RMB.

Renhuai has declared to National Quality Inspection Bureau for building national wine brand demonstration zone in 2013 and is allowed to be the first demonstration point of Renhuai Maotai-flavor liquor. This measure needs at least three years.

How to establish such a famous brand?

Firstly, the basic is to own famous brand.

Secondly, it must have relating enterprises. Marketing subject is the key instead of being conducted by government.

Thirdly, the quality of wine should be constant. The constancy of wine depends not only on production process, but also on final consumption. That is to say, fake wine should be refused firmly. Renhuai's self-market 
must stick to sincere marketing. However, this is not enough. It also needs local government to act as the leader to create a justice and fair marketing environment.

Last, to make sure the products are of high-quality, all enterprises should be insist on Maotai-flavor's traditional production arts. Under the good example of Maotai Group, cooperating with others advanced technology taken in from out areas, to be creative, and to protect Maotai-flavor liquor's traditional unique crafts perfectly.

With regard to marketing, Renhuai government creates a integrity platform to allow all enterprises to join in. In this year, Renhuai government starts a China project for the sake of making more people to know the highquality and the beneficial point of Renhuai Maotai-flavor liquor, hoping more and more people to understand Renhuai Maotai-flavor liquor and fall in love with it.

\section{Conclusions}

Renhuai wine industry should stick to the scientific development concept and carry out three main strategies of "developing the city economically, powering the city with brand, flourishing the city depending on tourism", taking every opportunity to promote Renhuai wine industry, protecting with science standpoint and exploitation rationally, relying on the "depend on Maotai, serve Maotai, develop with mutual benefits, seek mutual development” as guiding ideology and putting all-force to support Maotai Group.

To catch the key point and understand the authorities' profound strategy, the culture of wine and custom should be anchor-holden throughout the whole production process of wine study. In a word, Renhuai Maotai-flavor liquor constantly makes intellectual choices and enriches the long histories for wine culture. It strives for the amazing development, perseveres in hard struggle, has aggressive courage in heart, takes the responsibility of "the next ten years the Chinese liquor depends on Guizhou; Guizhou wine relies on Renhuai". It becomes the leading wine enterprise in Chinese industry.

\section{Acknowledgements}

For the first place, I would like to show my deepest gratitude to my supervisor, Dr. Li Yazhi, a respectable, responsible and resourceful scholar, who has provided me with valuable guidance in every stage of the writing of this thesis. Without her enlightening instruction, impressive kindness and patience, I could not have completed my thesis. Her keen and vigorous academic observation enlightens me not only in this thesis but also in my future study. I shall extend my thanks to Ms. Li for all her kindness and help. I would also like to thank all my teachers and family who have helped me develop the fundamental and essential academic competence. My sincere appreciation also goes to my friends, especially my two best friends who helped me with the material searching, for their encouragement and support.

\section{References}

[1] Kotler, P. (2001) Marketing Management. Tsinghua University Press, Beijing.

[2] Jin Qian Online-Guizhou Daily. 2013-09-06. http://www.gog.cn/

[3] (2014) Guizhou Chishui River Basin Ecological Civilization System Reform Press Conference. The Main Data Bulletin for the Sixth National Census (No. 1).

[4] (2011) The Main Data Bulletin for the Sixth National Census (No. 1). National Bureau of Statistics of the People's Republic of China.

[5] Jin Qian Online-Guizhou Metropolis Daily, 2008-08-19. http://www.gog.cn/

[6] Jin Qian Online-Guizhou Liquor Network. http://www.gog.cn/

[7] Guizhou Daily 2013-09-11. http://www.gog.cn/

[8] “Let the World Taste Chinese Maotai-Flavor, Let Maotai-Flavor Achievement 'Renhuai Velocity”” Speech by Renhuai Mayor Fang Xinguo; The China News Service Bureau of Guizhou on 2014-09-25. 